\title{
The Edinburgh \\ COMPANION TO THE \\ Critical Medical \\ Humanities
}

\author{
General Editors \\ Anne Whitehead And Angela Woods \\ Associate Editors \\ Sarah Atkinson, Jane Macnaughton \\ AND JENNIFER RICHARDS
}


Edinburgh University Press is one of the leading university presses in the UK. We publish academic books and journals in our selected subject areas across the humanities and social sciences, combining cuttingedge scholarship with high editorial and production values to produce academic works of lasting importance. For more information visit our website: www.edinburghuniversitypress.com

(C) editorial matter and organisation General Editors Anne Whitehead and Angela Woods and Associate Editors Sarah Atkinson, Jane Macnaughton and Jennifer Richards, 2016

(C) the chapters their several authors, 2016

Edinburgh University Press Ltd

The Tun - Holyrood Road, 12(2f) Jackson's Entry, Edinburgh EH8 8PJ

Typeset in 10/13 Adobe Sabon by

IDSUK (DataConnection) Ltd, and

printed and bound in Great Britain by

CPI Group (UK) Ltd, Croydon CR0 4YY

A CIP record for this book is available from the British Library

ISBN 9781474400046 (hardback)

ISBN 9781474400053 (webready PDF)

ISBN 9781474414555 (epub)

The right of Anne Whitehead, Angela Woods, Sarah Atkinson, Jane Macnaughton and Jennifer Richards to be identified as the editors of this work has been asserted in accordance with the Copyright, Designs and Patents Act 1988, and the Copyright and Related Rights Regulations 2003 (SI No. 2498). 